\title{
Long-term clinical follow-up of the resorbable magnesium scaffolds in acute coronary syndrome patients
}

\author{
Adrian Włodarczakk*, Magdalena Łanocha*, Maciej Lesiak³, Johan Benett', Marek Szudrowicz', Artur Jastrzębski', \\ Maciej Pęcherzewski', Jan Jakub Kulczycki', Łukasz Furtan', Karol Turkiewicz', Andrzej Korda'
}

'Department of Cardiology, MCZ Hospital, Lubin, Poland

${ }^{2}$ St. Adalbert's Hospital, Poznań, Poland

${ }^{3}$ Department of Cardiology, Poznan University of Medical Sciences, Poznań, Poland

${ }^{4}$ Department of Cardiovascular Medicine, University Hospitals Leuven, Leuven, Belgium

*Both authors equally contributed to the study.

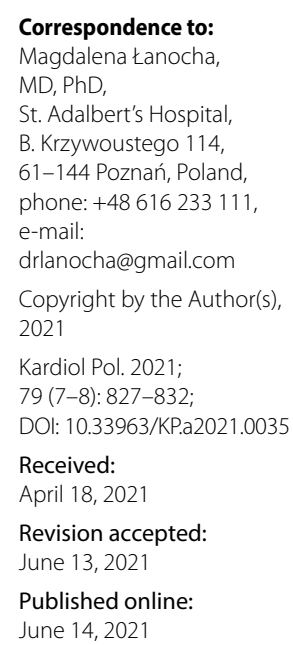

Correspondence to: Magdalena Łanocha, $\mathrm{MD}, \mathrm{PhD}$,

St. Adalbert's Hospital, B. Krzywoustego 114,

61-144 Poznań, Poland phone: +48616233111 , e-mail:

drlanocha@gmail.com

Copyright by the Author(s), 2021

Kardiol Pol. 2021;

79 (7-8): 827-832;

DOI: 10.33963/KP.a2021.0035

Received:

April 18, 2021

Revision accepted: June 13, 2021

Published online: June 14, 2021

\section{A B STRACT}

Background: Research on the resorbable magnesium scaffolds (RMSs) has shown their safety and effectiveness in stable clinical conditions. It seems that this new therapeutic option could be promising for selected acute coronary syndrome (ACS) patients.

Aims: Our analysis aims to analyze the long-term performance of RMSs among ACS patients.

Methods: The study population consisted of consecutive ACS patients treated with the implantation of at least one RMS. The Magmaris ACS Registry was designed as a single-arm observational registry in the 'real-world' treatment practice setting.

Results: The study population consisted of 193 patients, predominantly male (78\%), at a mean (SD) age of 64 (9) years and with typical risk factors of ACS. Unstable angina (UA) was the indication for revascularization in $32.1 \%$, non-ST-segment elevation myocardial infarction (NSTEMI) in $65.8 \%$ and ST-segment elevation myocardial infarction (STEMI) only in $2.1 \%$. During the mean 24 months of follow-up, ten cases (5.2\%) of target lesion failure (TLF) were diagnosed, of which five cases (2.6\%) were clinically driven target lesion failure (CD-TLR), four cases (2.1\%) were asymptomatic scaffold restenosis and one case (0.5\%) was target vessel myocardial infarction (TV-MI). No cardiac deaths and 2 non-cardiac deaths (2.2\%, both strokes) were observed. No cases of scaffold thrombosis were observed during the median 24-month follow-up.

Conclusions: The use of the RMSs in selected ACS patients is associated with procedural safety and promises early and long-term clinical efficacy and safety outcomes. Appropriate lesion selection is the key to the long-term success of bioresorbable technology in this patient population.

Key words: acute coronary syndrome, long-term outcome, resorbable magnesium scaffolds

Kardiol Pol 2021; 79, 7-8: 827-832

\section{INTRODUCTION}

Coronary stents have evolved significantly for the last four decades and have led to improvements in the treatment of patients' with coronary artery disease [1]. Bioresorbable scaffolds (BRSs) were designed to provide all the short-term benefits of permanent stents and, moreover, to relieve potential long-term adverse effect of metallic cage [2].

Although there has been some concern in bioresorbable technology because of increased rates of scaffold thrombosis (ScT), the newer generation of scaffolds have reopened a viable path to the 'leaving-nothing-behind' strategy [3, 4]. Resorbable magnesium scaffolds (RMSs), with their unique properties, have the potential to be an alternative to metallic drug-eluting stents, especially in the setting of the acute coronary syndrome (ACS) [5].

This analysis is the first to describe the long-term performance of RMSs in patients presenting with ACS.

\section{METHODS}

The study population consisted of consecutive ACS patients treated with the implantation of at least one magnesium Magmaris scaffold (BIOTRONIK AG, Bulach, Switzerland) [6]. The patients were treated between 2016 and 2020 in a single high-volume interventional cardiology center with 
WHAT'S NEW?

The use of the Magmaris resorbable magnesium scaffolds (RMSs) in selected acute coronary syndrome (ACS) patients is associated with procedural safety, and it promises early and long-term clinical outcomes. Our analysis is the first to describe the long-term performance of RMS in ACS setting. At a median of 24 months follow-up, a target lesion failure (TLF) rate of 5.2\% was observed, of which $2.6 \%$ were clinically driven target lesion failure (CD-TLR) and $0.5 \%$ target vessel myocardial infarction (TV-MI). No cases of scaffold thrombosis were observed during follow-up. Apropriate patient selection is the key to the longterm success of bioresorbable technology.

a large amount of experience with BRSs technology. On admission, all ACS patients were screened according to the previously described inclusion and exclusion criteria (Table 1) [6]. The Magmaris ACS Registry was designed as a prospective single-arm observational study in the setting of 'real-world' treatment practice [6]. The patients were managed as per current standard guidelines. The percutaneous coronary intervention ( $\mathrm{PCl}$ ) strategy, including the selection of medication, stent/scaffolds, and the use of intravascular imaging guidance, was left to the discretion of the operators. Patients received dual antiplatelet therapy (DAPT) for 12 months [7]. Clinical follow-up was obtained by telephone consultation, 30 days after the index procedure and then annually for up to 5 years [6].

The primary endpoint was the rate of target lesion failure (TLF), which is defined as cardiac death, target vessel myocardial failure (TV-MI) or target lesion revascularization (TLR) at 1-year. The secondary endpoints included rates of major adverse cardiac events, which can be defined as the composite of all-cause death, myocardial infarction or target vessel revascularization (TVR), along with target vessel failure (TVF). TLR was defined as any repeated revascularization procedure (percutaneous or surgical) of the original target lesion site, including the scaffold and within $5 \mathrm{~mm}$ of the proximal and distal scaffold margins. TVR was defined as any revascularization procedure occurring within the major epicardial vessel in which the scaffold was implanted, or its branches were. TVF was defined as cardiac death, TVMI or TVR. Definite and probable scaffold thromboses were

Table 1. Inclusion and exclusion criteria for the Polish ACS — Magmaris Registry

\begin{tabular}{|c|c|}
\hline Inclusion criteria & Exclusion criteria \\
\hline Subject is $\geq 18$ years of age & Thrombus in target vessel \\
\hline Acute coronary syndrome (ACS) & TIMI flow 0 in target vessel \\
\hline $\begin{array}{l}\text { Target lesion stenosis by visual } \\
\text { estimation: }>50 \%-<100 \% \text { and TIMI } \\
\text { flow } \geq 1\end{array}$ & Severe calcification in target vessel \\
\hline $\begin{array}{l}\text { Reference vessel diameter between } \\
2.7 \text { and } 3.7 \mathrm{~mm} \text { by visual estimation }\end{array}$ & $\begin{array}{l}\text { Ostial target lesion within } 5.0 \mathrm{~mm} \\
\text { of vessel origin }\end{array}$ \\
\hline $\begin{array}{l}\text { Target lesion length } \leq 21 \mathrm{~mm} \text { by } \\
\text { quantitative coronary angiography } \\
\text { (QCA) or by visual estimation }\end{array}$ & $\begin{array}{l}\text { Unsuccessful predilatation, here de- } \\
\text { fined as residual stenosis rate more } \\
\text { than } 20 \% \text { by visual estimation }\end{array}$ \\
\hline $\begin{array}{l}\text { Subject is eligible for dual antipla- } \\
\text { telet therapy }\end{array}$ & Planned surgery within 6 months \\
\hline $\begin{array}{l}\text { Subject is willing to sign a patient } \\
\text { informed consent form }\end{array}$ & $\begin{array}{l}\text { Known allergies to acetylsalicylic } \\
\text { acid, clopidogrel, ticlopidine, } \\
\text { heparin or any other anticoagulant/ } \\
\text { antiplatelet drug required for the } \\
\text { procedure }\end{array}$ \\
\hline
\end{tabular}

defined according to the Academic Research Consortium definitions [8].

All endpoints were evaluated at 30 days, one year and up to 5 years. The local ethics committee approved the study protocol, and the principles of the Declaration of Helsinki were followed. Written informed consent was obtained from each patient.

The device has previously been described [9-12]. The backbone of Magmaris is made of an absorbable magnesium (Mg) alloy. The square-shaped, electro-polished struts are $150 \mu \mathrm{m} \times 150 \mu \mathrm{m}$ in thickness and width, respectively. The surface is coated with $7 \mu \mathrm{m}$ of the biodegradable PLLA BIOlute polymer and loaded with sirolimus. The process of Mg alloy resorption starts at the backbone's surface and continues inward until only an amorphous footprint of amorphous calcium phosphate is left instead of the struts. About $95 \%$ of $\mathrm{Mg}$ is resorbed within 12 months. The following scaffold lengths were implanted 15,20 , and $25 \mathrm{~mm}$, with scaffold diameters of 3.0 and $3.5 \mathrm{~mm}$.

\section{Statistical analysis}

Continuous variables are expressed as mean (standard deviation) or median (interquartile ranges) for normally or non-normally distributed variables, respectively. The normality of distribution was assessed using the Kolmogorov-Smirnov and Lilliefors tests. Nominal variables were presented as numbers and percentages. Cumulative event rates were estimated using the Kaplan-Meier method. Statistical analysis was performed using SPSS version 20.0 (IBM Corp., Armonk, NY, USA).

\section{RESULTS}

The final study population comprised 191 patients due to two cases of unsuccessful RMSs delivery, followed by bailout regular drug-eluting stents (DESs) implantation. The baseline clinical and lesion characteristics of the enrolled patients are shown in Table 2 . The patients were predominantly male (78\%), at a mean (SD) age of 64 (9) years and with typical ACS risk factors. History of previous myocardial infarction and percutaneous interventions were noticed in $31.1 \%$ and $40.4 \%$ of the patients, respectively. UA was the indication for $\mathrm{PCl}$ in $32.1 \%$, non-ST-segment elevation myocardial infarction (NSTEMI) in 65.8\%, and ST-segment elevation myocardial infarction (STEMI) only in $2.1 \%$. A thrombolysis in myocardial infarction (TIMI) flow of 2 or 3 at baseline was observed in all patients. Most le- 
Table 2. Baseline clinical, laboratory and lesions findings

\begin{tabular}{lc}
\multicolumn{1}{c|}{ Variables } & N $=193$ patients \\
\hline Age, years & $64(9)$ \\
Male & $150 / 193(77.7)$ \\
Presentation & \\
Unstable angina & $62 / 193(32.1)$ \\
NSTEMI & $127 / 193(65.8)$ \\
STEMI & $4 / 193(2.1)$ \\
Hypertension & $172 / 193(89.1)$ \\
Dyslipidemia & $156 / 193(80.8)$ \\
Diabetes mellitus & $70 / 193(36.3)$ \\
Atrial fibrillation & $10 / 193(5.2)$ \\
Tobacco use & $93 / 193(48.2)$ \\
Current tobacco use & $44 / 193(22.8)$ \\
Prior myocardial infarction & $60 / 193(31.1)$ \\
Prior PCl & $78 / 193(40.4)$ \\
Prior CABG & $3 / 193(1.6)$ \\
Ejection fraction & $60(10)$ \\
Laboratory & \\
Troponin T, ng/ml, base & $14.9(10.7-33.5)$ \\
Troponin T, ng/ml, max & $54.2(19.0-210.3)$ \\
CK-MB, ng/ml, base & $2.8(2.0-5.3)$ \\
CK-MB, ng/ml, max & $5.8(2.8-14.6)$ \\
Culprit lesion location & $\mathrm{N}=194$ lesions \\
Right coronary artery & $62 / 194(32.0)$ \\
Left anterior descending artery & $80 / 194(41.2)$ \\
Left circumflex artery & $52 / 194(26.8)$ \\
Syntax Score & $7(2-9)$ \\
A/B1 Lesion Class & $144 / 194(74)$ \\
\hline &
\end{tabular}

Values are mean (SD), median (IQR) or $\mathrm{n}(\%)$.

Abbreviations: $C A B G$, coronary artery bypass grafting; CK-MB, creatine phosphokinase-muscle/brain; NSTEMI, non-ST-segment elevation myocardial infarction; $\mathrm{PCl}$, percutaneous coronary intervention; STEMI, ST-segment elevation myocardial infarction

sions (74\%) were classified as type $\mathrm{A}+\mathrm{B} 1$ according to the AHA/ACC classification.

Scaffold implantation and sizing were done under the Magmaris instructions-for-use (IFU) document using the 4P strategy as the golden rule. Predilatation was mandatory and performed in all lesions with a non-compliant balloon, which was sized according to the vessel's reference diameter (Table 3). In total, 204 scaffolds were implanted. Ten lesions required implantation of two edge-to-edge scaffolds mainly caused by lesion length underestimation. In one patient, multivessel scaffolding was performed during the index procedure. Post-dilatation was mandatory and performed in $100 \%$ of the lesions with a non-compliant balloon. Imaging guidance in the form of optical coherence tomography (OCT) was performed in $20 \%$ of the patients and was done more extensively in the early stage of the study. The final TIMI 3 flow was achieved in $100 \%$ of the patients. During the index procedure, 7 cases of edge dissection were recognized; in 3 cases, additional
Table 3. Procedural technique and angiographic outcomes

\begin{tabular}{lc}
\multicolumn{1}{c}{ Variables } & \\
\hline Procedures (PCI) & $\mathrm{N}=193$ \\
Predilatation performed with NC balloon & $193 / 193(100.0)$ \\
OCT-guided PCI & $39 / 193(20.2)$ \\
Implanted scaffolds & $\mathrm{N}=204$ \\
Mean scaffold length, mm & $20.7(3.3)$ \\
Mean scaffold diameter, mm & $3.3(0.3)$ \\
Mean deployment pressure, Atm & $(0.8)$ \\
$>1$ scaffold for lesion & $10 / 193(5.2)$ \\
Post-dilatation performed with NC balloon & $202 / 204(99.0)$ \\
\hline
\end{tabular}

Values are mean (SD) or $\mathrm{n}(\%)$.

Abbreviations: NC balloon, non-compliant balloon; OCT, optical coherence tomography; $\mathrm{PCl}$, percutaneous coronary intervention

scaffolds were required, and in 4 cases, additional DESs were implanted.

In 2 cases (1.0\%), a transient small side branch (SB) occlusion occurred after the implantation of RMSs, requiring recrossing with the guidewire through the RMSs' strut into the SB and opening the SB with a small balloon in one case. No SB bail-out stenting was needed. On discharge, all patients received DAPT, of whom 117 (61\%) were on aspirin plus ticagrelor, and 74 (39\%) were on aspirin plus clopidogrel.

To date, a total of 153 patients have reached 1-year follow-up. All patients remained on the prescribed DAPT for 12 months unless the additional revascularization required appropriate DAPT elongation.

During this period, 2 cases of clinically driven target lesion revascularizations (CD-TLR) (1.3\%) and 1 case of TVMI (0.7\%) were observed. Additionally, 14 patients were scheduled for stage procedures of non-culprit vessel after the index $\mathrm{PCl}$, whereby 1 case $(0.7 \%)$ of asymptomatic scaffold restenosis was diagnosed. Two fatal stroke cases were recognized, with consequent non-cardiac deaths in the second and seventh months after PCI. No scaffold thrombosis was observed.

Two-year clinical outcomes are available in 100 cases. During the second year of follow-up, three cases of CD-TLR (3.0\%) were observed (Table 4). Further three cases (3\%) of asymptomatic scaffold restenosis were found due to control angiography. Since the index procedure, $70(36.6 \%)$ patients from our study group underwent control angiography scheduled mainly by their family doctor or cardiologist. During the mean 24 months of follow-up, nine cases (4.7\%) of in-scaffold restenosis were observed. Scaffold failure occurred mainly because of a partial collapse of the magnesium scaffold or diffused tissue proliferation. The cumulative data are presented in Table 4. To date, no cardiac death or scaffold thrombosis has occurred and no loss to follow-up occurred. 
Table 4. Clinical outcome of the study population

\begin{tabular}{|c|c|c|c|c|}
\hline & \multicolumn{3}{|c|}{ Follow-up } & \multirow{2}{*}{$\begin{array}{c}\text { Cumulative } \\
24(17-33) \text { month } \\
(n=191)\end{array}$} \\
\hline & $\begin{array}{l}0-30 \text { day } \\
(n=191)\end{array}$ & $\begin{array}{c}0-12 \text { month } \\
(n=153)\end{array}$ & $\begin{array}{l}12-24 \text { month } \\
(n=100)\end{array}$ & \\
\hline TLF & 0 & $4(2.6)$ & $6(6.0)$ & $10(5.2)$ \\
\hline Cardiac death & $0(0)$ & $0(0)$ & $0(0)$ & $0(0)$ \\
\hline TV-MI & $0(0)$ & $1(0.7)$ & $0(0)$ & $1(0.5)$ \\
\hline CD-TLR & $0(0)$ & $2(1.3)$ & $3(3.0)$ & $5(2.6)$ \\
\hline Asymptomatic-TLR & $0(0)$ & $1(0.7)$ & $3(3)$ & $4(2.1)$ \\
\hline Scaffold thrombosis & $0(0)$ & $0(0)$ & $0(0)$ & $0(0)$ \\
\hline All death & $0(0)$ & $2(1.3)$ & $0(0)$ & $2(1.0)$ \\
\hline All-MI & $0(0)$ & $3(2.0)$ & $3(3.0)$ & $6(3.1)$ \\
\hline Any-revascularization & $0(0)$ & $17(11.1)$ & $13(13.0)$ & $30(15.7)$ \\
\hline Stroke & $0(0)$ & $3(2.0)$ & $0(0)$ & $3(1.6)$ \\
\hline
\end{tabular}

Values are median (IQR) or $\mathrm{n}(\%)$.

Abbreviations: CD-TLR, clinically driven target lesion revascularization; MI, myocardial infarction; TLF, target lesion failure; TLR, target lesion revascularization; TV-MI, target vessel myocardial infarction

\section{DISCUSSION}

The recent experience of RMSs use is still limited, especially regarding long-term follow-up. Initially, Magmaris implantations were limited to patients with a long life expectancy, clinically stable and with short de novo lesions [13-16]. Our Magmaris Registry is one of the first in the ACS (unstable angina/NSTEMI) setting and provides a long-term analysis of magnesium scaffold performance [17].

The crucial part of the project was the proper selection of ACS patients. Relatively young patients with low/mild risk factors and preserved ejection fraction were given preference during screening. Although STEMI patients were not excluded from the Registry, the other exclusion criteria and the difficulty to adhere to the 4P strategy significantly limited the STEMI population in our study group. We believe that appropriately selected patients will achieve the most significant benefit from treatments using this promising technology; the magnesium scaffold is not a therapeutic option for every patient.

In addition to demographic factors, lesion characteristics played the second most important role. Non-calcified, focal, proximal segment lesions were most often selected for Magmaris implantation. However, heavy calcification, challenging tortuosity or angulation, diffuse disease, or thrombus presence in the culprit vessel excluded the patient from our registry. Over time, we obtained good experience with scaffolding longer lesions requiring more than one Magmaris. It seems a desirable option to treat a long soft lesion with RMSs, hence avoiding the full metal jacket design.

Early results of RMSs implantation are strongly correlated with the technical aspects of the procedure [6]. Adherence to proper implantation techniques, precisely the 4P strategy (proper patient and lesion selection, proper scaffold sizing, predilatation for lesion preparation and post-dilatation) reduces the risk of mistakes which have been observed during implantations of first-generation BRSs $[15,16]$. Additionally, the previous experience of Absorb scaffolds raised a safety concern because of the increased ScT rates compared with metallic stents [18]. In a preclinical study, the Magmaris scaffold had significantly less platelet deposition and thrombus formation along with less inflammatory cell deposition than the Absorb or the Orsiro stent (BIOTRONIK) or even a 316L stainless steel stent with the same geometry and design [19, 20]. A 2-year analysis of the pooled population of the BIOSOLVE-II and BIOSOLVE-III trials confirmed no probable or definite SCT [14]. The results of the BIOSOLVE-II and international registry BIOSOLVE-IV — or even the high-risk population of the MAGSTEMI trial - have released the metallic magnesium scaffold from the ScT 'class effect' [14-16, 21, 22]. Our study has confirmed that the use of a magnesium scaffold, even in the ACS setting, does not raise any concerns about increased SCT.

Estimation of the RMSs' resorption period is an essential factor for setting DAPT duration. During the resorption phase, scaffold discontinuity and polymer breakdown are observed, and it may increase the risk of thrombus formation. Therefore, 12 months of DAPT is recommended for all ACS Magmaris patients. The duration of DAPT needs to be balanced against the increased risk of bleeding events. Unfortunately, in our study, two cases of fatal stroke occurred during the 12 months of DAPT.

On the other hand, the shorter period of bioresorption could lead to an early loss of mechanical support, resulting in scaffold's 'late recoil' and restenosis [23]. In the 6- and 12-month angiographic follow-up of the BIOSOLVE-II trial, the late loss in-scaffold were $0.37(0.25) \mathrm{mm}$ and $0.39(0.27)$ $\mathrm{mm}$, respectively [24,25]. At one year of the subgroup analysis of the first 400 patients of the BIOSOLVE-IV, the CD-TLF rate was $4.3 \%$, which is comparable to the results of the FANTOM II trial, where major adverse cardiac events occurred in $4.2 \%$ and target lesion failure in $4.2 \%$ of the 240 patients at 12 months [26]. However, in our population, the CD-TLR barely reached $1.3 \%$ and cumulative TLF $2.6 \%$ at 1-year follow-up. The 2-year TLF rate was $5.9 \%$ in a pooled population of the BIOSOLVE-II and BIOSOLVE-III trials [14]. Despite this, both of the above trials enrolled stable pa- 
tients with simple lesions. In our ACS Magmaris population, the 2-year cumulative TLF reached 5.2\%. Although caution should be applied in interpreting the results across studies because of the small number of cases, these findings support the evidence for favorable long-term results of using Magmaris in the ACS setting. The latest presented pooled analysis of BIOSOLVE-II and BIOSOLVE-III demonstrated similar rates of TLF (6.4\%) and clinically driven revascularization (3.7\%) at the 36-month follow-up when compared with second-generation DES [27].

In the present study, the Magmaris RMSs demonstrated excellent safety results through a 12 - to $24-$ month clinical follow-up. The data is very encouraging for magnesium scaffolds as a therapeutic option for patients presenting with UA or non-ST-segment elevation ACS. Although Magmaris ACS procedures appear safe and feasible, larger randomized studies with longer follow-ups are needed, especially in the ACS setting.

\section{Study limitations}

A low number of study patients, the setting restricted mainly to NSTEMI or UA patients and an observational, single-arm design are the relevant limitations of our study. No control group was available to compare the use of the scaffold with DES. Admittedly there was also a selection bias as operators were prompted to choose less complex lesions for Magmaris implantation.

\section{CONCLUSIONS}

The use of the Magmaris RMS in selected ACS patients is associated with procedural safety and promises early and long-term clinical and safety outcomes. Appropriate patient selection is the key to the long-term success of bioresorbable technology. Further evaluation in larger prospective randomized controlled trials is needed before scaffold technology can be rolled out to everyday use in interventional cardiology.

\section{Article information}

Conflict of interest: $M\lfloor$ has received speaking fees from Biotronik AG. JB has received research grants and consultancy fees from Biotronik; AG, research grants and speaking fees from Abbott Vascular and consultancy fees from Boston Scientific. ML has received speaking fees from Biotronik AG. The other authors have no conflicts of interest to declare.

Open access: This article is available in open access under Creative Common Attribution-Non-Commercial-No Derivatives 4.0 International (CC BY-NC-ND 4.0) license, allowing to download articles and share them with others as long as they credit the authors and the publisher, but without permission to change them in any way or use them commercially. For commercial use, please contact the journal office at kardiologiapolska@ptkardio.pl.

How to cite: Włodarczak $A$, Łanocha M, Lesiak M, et al. Long-term clinical follow-up of the resorbable magnesium scaffolds in acute coronary syndrome patients. Kardiol Pol. 2021; 79(7-8): 827-832, doi: 10.33963/KP.a2021.0035.

\section{REFERENCES}

1. Serruys PW, de Jaegere P, Kiemeneij F, et al. A comparison of balloon-expandable-stent implantation with balloon angioplasty in patients with coronary artery disease. Benestent Study Group. N Engl J Med. 1994; 331(8): 489-495, doi: 10.1056/NEJM199408253310801, indexed in Pubmed: 8041413.

2. Serruys PW, Garcia-Garcia HM, Onuma Y. From metallic cages to transient bioresorbable scaffolds: change in paradigm of coronary revascularization in the upcoming decade? Eur Heart J. 2012; 33(1): 16-25b, doi: 10.1093/eurheartj/ehr384, indexed in Pubmed: 22041548.

3. Serruys PW, Chevalier B, Sotomi Y, et al. Comparison of an everolimus-eluting bioresorbable scaffold with an everolimus-eluting metallic stent for the treatment of coronary artery stenosis (ABSORB II): a 3 year, randomised, controlled, single-blind, multicentre clinical trial. Lancet. 2016; 388(10059): 2479-2491, doi: 10.1016/S0140-6736(16)32050-5, indexed in Pubmed: 27806897.

4. Wykrzykowska JJ, Kraak RP, Hofma SH, et al. AIDA Investigators. Bioresorbable scaffolds versus metallic stents in routine $\mathrm{PCI}$. N Engl J Med. 2017; 376(24): 2319-2328, doi: 10.1056/NEJMoa1614954, indexed in Pubmed: 28402237.

5. Waksman R, Lipinski MJ, Acampado E, et al. Comparison of acute thrombogenicity for metallic and polymeric bioabsorbable scaffolds: magmaris versus absorb in a porcine arteriovenous shunt model. Circ Cardiovasc Interv. 2017; 10(8): e004762, doi: 10.1161/CIRCINTERVENTIONS.116.004762, indexed in Pubmed: 28801538.

6. Wlodarczak A, Lanocha M, Jastrzebski A, et al. Early outcome of magnesium bioresorbable scaffold implantation in acute coronary syndrome-the initial report from the Magmaris-ACS registry. Catheter Cardiovasc Interv. 2019; 93(5): E287-E292, doi: 10.1002/ccd.28036, indexed in Pubmed: 30537203.

7. Valgimigli M, Bueno H, Byrne RA, et al. 2017 ESC focused update on dual antiplatelet therapy in coronary artery disease developed in collaboration with EACTS: The Task Force for dual antiplatelet therapy in coronary artery disease of the European Society of Cardiology (ESC) and of the European Association for Cardio-Thoracic Surgery (EACTS). Eur Heart J. 2018; 39(3): 213-260, doi: 10.1093/eurheartj/ehx419, indexed in Pubmed: 28886622.

8. Cutlip DE, Windecker S, Mehran R, et al. Academic Research Consortium. Clinical end points in coronary stent trials: a case for standardized definitions. Circulation. 2007; 115(17): 2344-2351, doi: 10.1161/CIRCULATIONAHA.106.685313, indexed in Pubmed: 17470709.

9. Waksman $R$, Zumstein $P$, Pritsch $M$, et al. Second-generation magnesium scaffold Magmaris: device design and preclinical evaluation in a porcine coronary artery model. Eurolntervention. 2017; 13(4): 440-449, doi: 10.4244/EIJ-D-16-00915, indexed in Pubmed: 28262623.

10. Joner $M$, Ruppelt $P, Z$ Zumstein $P$, et al. Preclinical evaluation of degradation kinetics and elemental mapping of first- and second-generation bioresorbable magnesium scaffolds. Eurolntervention. 2018; 14(9): e1040-e1048, doi: 10.4244/EIJ-D-17-00708, indexed in Pubmed: 29469029.

11. Rapetto C, Leoncini M. Magmaris: a new generation metallic sirolimus-eluting fully bioresorbable scaffold: present status and future perspectives. J Thorac Dis. 2017; 9(Suppl 9): S903-S913, doi: 10.21037/jtd.2017.06.34, indexed in Pubmed: 28894596.

12. Bennett J, De Hemptinne Q, McCutcheon K. Magmaris resorbable magnesium scaffold for the treatment of coronary heart disease: overview of its safety and efficacy. Expert Rev Med Devices. 2019; 16(9): 757-769, doi: 10.1080/17434440.2019.1649133, indexed in Pubmed: 31345074.

13. Fajadet J, Haude $M$, Joner $M$, et al. Magmaris preliminary recommendation upon commercial launch: a consensus from the expert panel on 14 April 2016. Eurolntervention. 2016; 12(7): 828-833, doi: 10.4244/EIJV12I7A137, indexed in Pubmed: 27639734.

14. Haude $M$, Ince $H$, Kische $S$, et al. Sustained safety and clinical performance of a drug-eluting absorbable metal scaffold up to 24 months: pooled outcomes of BIOSOLVE-II and BIOSOLVE-III. Eurolntervention. 2017; 13(4): 432-439, doi: 10.4244/EIJ-D-17-00254, indexed in Pubmed: 28504239. 
15. Haude $M$, Ince $H$, Toelg $R$, et al. Safety and performance of the second-generation drug-eluting absorbable metal scaffold (DREAMS $2 \mathrm{G}$ ) in patients with de novo coronary lesions: three-year clinical results and angiographic findings of the BIOSOLVE-II first-in-man trial. EuroIntervention. 2020; 15(15): e1375-e1382, doi: 10.4244/EIJ-D-18-01000, indexed in Pubmed: 30803936.

16. Wlodarczak A, Garcia LA, Karjalainen PP, et al. Magnesium 2000 postmarket evaluation: guideline adherence and intraprocedural performance of a sirolimus-eluting resorbable magnesium scaffold. Cardiovasc Revasc Med. 2019; 20(12): 1140-1145, doi: 10.1016/j.carrev.2019.02.003, indexed in Pubmed: 30833209.

17. Łanocha M, Włodarczak A, Szudrowicz M, et al. Multimodality imaging results of neointimal healing after magnesium scaffold implantation in an acute coronary syndrome setting. Kardiol Pol. 2021 [Epub ahead of print], doi: 10.33963/KP.15911, indexed in Pubmed: 33784036.

18. Stone GW, Kimura T, Gao R, et al. Time-varying outcomes with the absorb bioresorbable vascular scaffold during 5-year follow-up: a systematic meta-analysis and individual patient data pooled study. JAMA Cardiol. 2019; 4(12): 1261-1269, doi: 10.1001/jamacardio.2019.4101, indexed in Pubmed: 31561250.

19. Lipinski MJ, Acampado E, Cheng Qi, et al. Comparison of acute thrombogenicity for magnesium versus stainless steel stents in a porcine arteriovenous shunt model. Eurolntervention. 2019; 14(13): 1420-1427, doi: 10.4244/EIJ-D-17-00958, indexed in Pubmed: 29741484.

20. Waksman R, Lipinski MJ, Acampado E, et al. Comparison of acute thrombogenicity for metallic and polymeric bioabsorbable scaffolds: magmaris versus absorb in a porcine arteriovenous shunt model. Circ Cardiovasc Interv. 2017; 10(8): e004762, doi: 10.1161/CIRCINTERVENTIONS.116.004762, indexed in Pubmed: 28801538.

21. Verheye $S$, Wlodarczak A, Montorsi P, et al. BIOSOLVE-IV-registry: Safety and performance of the Magmaris scaffold: 12-month outcomes of the first cohort of 1,075 patients. Catheter Cardiovasc
Interv. 2020 [Epub ahead of print], doi: 10.1002/ccd.29260, indexed in Pubmed: 32881396.

22. Sabaté $M$, Alfonso $F$, Cequier $A$, et al. Magnesium-based resorbable scaffold versus permanent metallic sirolimus-eluting stent in patients with st-segment elevation myocardial infarction: the MAGSTEMI randomized clinical trial. Circulation. 2019; 140(23): 1904-1916, doi: 10.1161/CIRCULATIONAHA.119.043467, indexed in Pubmed: 31553204.

23. Cubero-Gallego H, Vandeloo B, Gomez-Lara J, et al. Early collapse of a magnesium bioresorbable scaffold. JACC Cardiovasc Interv. 2017; 10(18): e171-e172, doi: 10.1016/j.jcin.2017.07.037, indexed in Pubmed: 28935085.

24. Haude $M$, Ince $H$, Abizaid A, et al. Safety and performance of the second-generation drug-eluting absorbable metal scaffold in patients with de-novo coronary artery lesions (BIOSOLVE-II): 6 month results of a prospective, multicentre, non-randomised, first-in-man trial. The Lancet. 2016; 387(10013): 31-39, doi: 10.1016/s0140-6736(15)00447-x, indexed in Pubmed: 26470647.

25. Haude $M$, Ince $H$, Abizaid $A$, et al. Sustained safety and performance of the second-generation drug-eluting absorbable metal scaffold in patients with de novo coronary lesions: 12-month clinical results and angiographic findings of the BIOSOLVE-II first-in-man trial. Eur Heart J. 2016; 37(35): 2701-2709, doi: 10.1093/eurheartj/ehw196, indexed in Pubmed: 27190094.

26. Chevalier B, Abizaid A, Carrié D, et al. Clinical and angiographic outcomes with a novel radiopaque sirolimus-eluting bioresorbable vascular scaffold. Circ Cardiovasc Interv. 2019; 12(6): e007283, doi: 10.1161/CIRCINTERVENTIONS.118.007283, indexed in Pubmed: 31177821.

27. Haude $M$, Ince $H$, Kische $S$, et al. TCT-188 safety and clinical performance of the drug-eluting absorbable metal scaffold in the treatment of subjects with de novo lesions in native coronary arteries at 36-month follow-up: BIOSOLVE-II and BIOSOLVE-III. J Am Coll Cardiol. 2019; 74(13): B187, doi: 10.1016/j.jacc.2019.08.247. 